\title{
Inhibitory Interactions Between Spiking and Nonspiking Local Interneurons in the Locust
}

\author{
M. Burrows \\ Department of Zoology, University of Cambridge, Cambridge CB2 3EJ, England
}

Simultaneous intracellular recordings were made from pairs of spiking and nonspiking local interneurons in the metathoracic ganglion of the locust to search for interactions that might underlie tactile and proprioceptive reflexes of a leg. A spike in a spiking local interneuron is followed after a consistent latency $(0.6 \pm 0.12 \mathrm{msec}$, mean \pm SD) by an IPSP in a particular nonspiking interneuron. The connection appears to be direct and chemically mediated. By contrast, manipulating the membrane potential of a nonspiking interneuron by injecting current through the recording electrode has no direct effect on a spiking local interneuron. The direct interactions between pairs of these local interneurons are thus one-way. If, however, the current injected into a nonspiking interneuron is sufficient to evoke a movement by exciting motor neurons, then the spiking interneuron can be excited or inhibited by the resulting reafference.

The spiking local interneurons have excitatory regions in their receptive fields formed by arrays of exteroreceptors or by proprioceptors at specific joints. The inhibitory connections mean that the postsynaptic nonspiking interneurons have corresponding inhibitory regions to their receptive fields. Several spiking local interneurons with similar receptive fields may converge onto one nonspiking interneuron. Some nonspiking interneurons, however, have larger receptive fields than an individual spiking interneuron, again indicating convergence of inputs. The specificity of the inhibitory connections preserves the spatial representation of sensory information for use in particular reflexes. For example, touching hairs on the ventral femur evokes a reflex extension of the tibia. Spiking interneurons excited by these receptors inhibit a nonspiking interneuron that would cause the opposing and therefore unwanted flexion movement. Viewed in this behavioral context, the pattern of connections between the local interneurons forms the basis of the circuitry for the local reflex adjustments of posture and locomotion.

The requirement of flexibility in the control of movement imposes constraints on the design of reflex pathways. If afferent fibers from muscle or joint receptors synapse directly upon motor neurons, as do vertebrate $1 \mathrm{~A}$ afferents (see Homma, 1976), insect chordotonal organs (Burrows, 1987), and some crustacean

\footnotetext{
Received Jan. 16, 1987; revised Apr. 21, 1987; accepted Apr. 21, 1987.

This work was supported by a grant from the SERC(UK). I thank Gilles Laurent for providing the data used in Figure 3, and my colleagues for their helpful comments on the manuscript.

Correspondence should be addressed to M. Burrows, Department of Zoology, University of Cambridge, Downing Strect, Cambridge CB2 3EJ, England.

Copyright (C) 1987 Society for Neuroscience $0270-6474 / 87 / 103282-11 \$ 02.00 / 0$
}

joint receptors (Blight and Llinás, 1980), then mechanisms for suppressing or overriding these afferent effects must bc present to allow voluntary movements to proceed. In crayfish, for example, two proprioceptive afferents that synapse directly on motor neurons receive a central drive in time with the locomotory rhythm (Sillar and Skorupski, 1986) that can reverse the sign of the reflex effects, depending on the phase of the movement (Skorupski and Sillar, 1986).

Reflex pathways that are initiated by stimulation of tactile receptors have greater scope for flexibility, in that the afferent signals are routed through interneurons. Indeed, the flexibility of stretch reflexes may also result in part from parallel pathways involving interneurons that excite the motor neurons (Taylor and Gottlieb, 1985). An understanding of the flexibility of motor control will thus rest heavily upon knowing the properties of these interneurons and the types of connections that they make.

In insects, the interneurons involved in both proprioceptive and tactile reflex pathways can be identified, so that their individual contributions to a movement can be assessed. Two iypes of local interneuron are involved in the control of limb movements of the locust. Spiking local interneurons act as primary integrators of sensory inputs by receiving direct inputs from tactile (Siegler and Burrows, 1983) and proprioceptive (Burrows, 1985, 1987) afferents. Each interneuron receives inputs from a specific array of receptors that make up its receptive field (Burrows and Siegler, 1985). In certain reflex pathways, just one of these interneurons may be interposed between the afferents and the participating motor neurons (Burrows and Siegler, 1982). The majority of pathways cannot, however, be explained solely by the contribution of these spiking local interneurons, and therefore the second type of local interneuron is also implicated. Nonspiking local interneurons control the pools of motor neurons required for the different patterns of limb movement (Burrows, 1980). They make excitatory or inhibitory connections with motor neurons and exert a fine and sustained control by the graded release of transmitter (Burrows and Siegler, 1978).

This paper shows that spiking local interneurons make inhibitory connections with nonspiking interneurons and places these connections in the context of known reflexes. The spatial information that is coded in the receptive fields of the spiking local interneurons is preserved, so that a specific reflex movement can occur when a particular array of receptors is stimulated.

\section{Materials and Methods}

Adult male and female locusts, Schistocerca gregaria (Forskal), were taken from our crowded culture and restrained ventral surface uppermost in plasticine. The femorotibial and tarsal joints of all the legs, as 
well as the head and abdomen, were free to move. The thorax was opened ventrally to expose the meso- and metathoracic ganglia, which were supported on a wax-coated platinum platform. The thorax was continuously perfused with saline at room temperature. The sheath of the metathoracic ganglion was treated with a $0.1 \%$ (wt/vol) solution of protease (Sigma type XIV) in saline for approximately $2 \mathrm{~min}$. Glass microelectrodes filled with $2 \mathrm{M}$ potassium acetate and with DC resistances of 50-80 M $\Omega$ were used to record from the soma of a spiking local interneuron and simultaneously from the neuropilar process of a nonspiking interneuron. All the spiking local interneurons that were studied have cell bodies at the ventral midline of the ganglion (Siegler and Burrows, 1984). They were characterized by their responses to stimulation of extero- or proprioceptors on one hindleg. To confirm identification, some interneurons were impaled with electrodes filled with $0.1 \mathrm{M}$ hexamminecobaltic chloride and stained by injection of this dye. The anatomy of these interneurons has been described elsewhere (Burrows and Siegler, 1984; Siegler and Burrows, 1984; Burrows, 1985). Nonspiking interneurons were identified according to established criteria (see Burrows and Siegler, 1978, for full details). The neurons did not spike during evoked movements of a hindleg or when depolarizing current was injected through the recording electrode. Some could be characterized by their effects on known motor neurons innervating muscles in a hindleg when they were depolarized with injected current. Identification was again confirmed by intracellular staining with cobalt (Pitman et al., 1972; Brogan and Pitman, 1981). The anatomy of these interneurons has been described elsewhere (Siegler and Burrows, 1979; Watkins et al., 1985). All recordings were stored on FM magnetic tape for later analysis and display on a Gould ES1000 recorder or, after capture on a digital oscilloscope, on an $X-Y$ plotter.

The results are based on 72 paired recordings from a nonspiking and a spiking local interneuron in 63 locusts. Interactions were found between 28 pairs. After initial experiments had demonstrated inhibitory connections, the search strategy was limited by maintaining recordings only from nonspiking interneurons with inhibitory regions to their receptive fields, while attempting to find a presynaptic spiking local interneuron.

\section{Results}

Touching an array of hairs on a specific region of a hindleg or moving a particular joint excites certain spiking local interneurons with cell bodies at the ventral midline of the metathoracic ganglion. At the same time, certain nonspiking local interneurons are inhibited. If a different region of the leg or a different joint is moved, then different spiking and nonspiking local interneurons are affected. The question is whether the inhibition of a nonspiking interneuron that results from specific exteroreceptive or proprioceptive input is caused by the spiking local interneurons. To answer this question, therefore, requires that pairs of spiking and nonspiking intcrncurons be found whosc receptive fields show some common regions and tests be made for possible interactions between them.

\section{Direct inhibitory connections between spiking and nonspiking interneurons}

A pair of interneurons affected by touching hairs on the dorsal distal femur is shown in Figure 1. In the absence of any applied stimulus, the sporadic spikes in the spiking local interneuron are accompanied by IPSPs in the nonspiking interneuron (Fig. $1 A$ ). Touching a few of the hairs evokes a burst of spikes in the spiking interneuron, each of which is followed by an IPSP in the nonspiking interneuron (Fig. $1 A$ ). The IPSPs have an exceptionally large amplitude of approximately $5 \mathrm{mV}$, and may sum to produce a tonic hyperpolarization of the membrane. Altering the membrane potential of the nonspiking interneuron with injected current changes the amplitude of the IPSPs, indicating that they are chemically mediated. To ascertain whether the IPSPs are caused by the spiking local interneuron, a pulse of current is injected into it to evoke spikes (Fig. $1 B$ ). Each spike
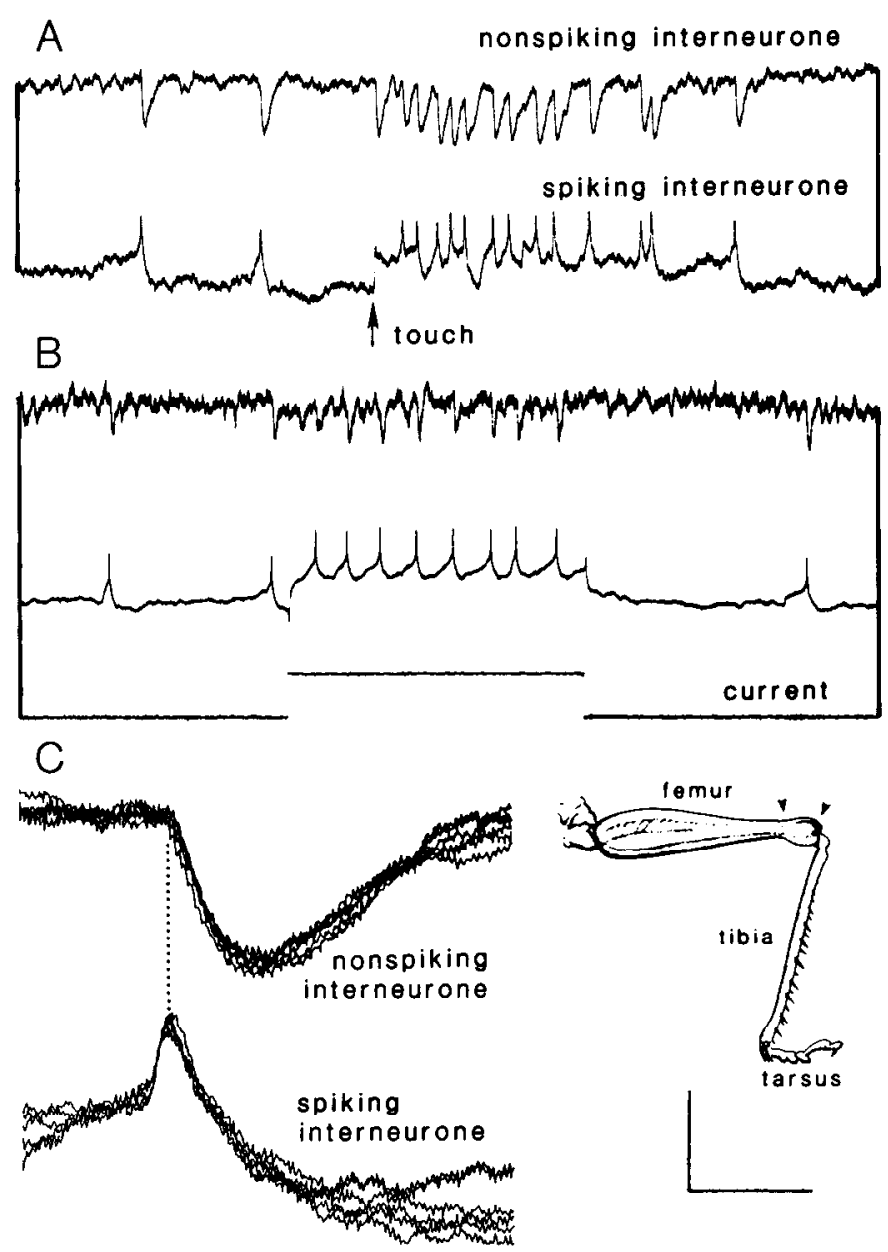

Figure 1. Inhibition of a nonspiking local interneuron by a spiking local interneuron that receives inputs from exteroreceptors. $A$, Touching hairs on the dorsal surface of the distal femur (arrow) evokes a burst of spikes in the spiking interneuron (lower trace) and large IPSPs in the nonspiking interneuron (upper trace). $B$, A depolarizing pulse of current injected into the spiking interneuron evokes spikes that are each followed by an IPSP in the nonspiking interneuron. $C$, Multiple sweeps triggered by the spike of the spiking interneuron show the consistent and short latency of the IPSP in the nonspiking interneuron. The diagram of the leg in this and other figures shows the distribution of receptors (arrowheads) that excite the spiking interneuron. The recordings in $A$ and $C$ are from one locust, those in $B$ from another. Calibration: Vertical: $A$, nonspiking interneuron, $10 \mathrm{mV} ; B, 2 \mathrm{mV} ; C, 3 \mathrm{mV} ; A$, spiking interneuron, $4 \mathrm{mV} ; B, 10 \mathrm{mV} ; C, 1.3 \mathrm{mV}$. Current, $1 \mathrm{nA}$; horizontal: $A, B, 250 \mathrm{msec} ; C, 10 \mathrm{msec}$.

evoked by the applied current is followed by an IPSP in the nonspiking interneuron. On an expanded time scale with several traces superimposed, each IPSP is seen to follow a spike with a short and constant latency (Fig. 1C).

A second pair of interneurons is affected by proprioceptive inputs activated when the tibia is forcibly extended (Fig. 2). Repetitive imposed movements of the tibia consistently evoke an excitation of the spiking interneuron and a hyperpolarization of the nonspiking interneuron (Fig. 2A). Flexor tibiae motor neurons also spike in a resistance reflex that opposes the imposed movement. If the tibia is extended and then held at that new position, the frequency both of spikes in the spiking interneuron and of the IPSPs contributing to the hyperpolarization of the nonspiking interneuron are sustained (Fig. $2 B$ ). Signal averages triggered by the spikes in the spiking interneuron show that an 
Figure 2. Inhibition of a nonspiking local interneuron by a spiking local interneuron that receives inputs from proprioceptors. $A$, Each imposed extension of the tibia (arrows) evokes spikes in the spiking local interneuron (middle trace) and IPSPs in the nonspiking interneuron (upper trace). Flexor libiae motor neurons (myogram on lower trace) also spike during each extension. $B$, A controlled movement of the tibia (monitored on lower trace) evokes an increase in the frequency of spikes in the spiking local interneuron and IPSPs that summate to hold the nonspiking interneuron hyperpolarized for the duration of the imposed extension. $C$, Signal averages (128 sweeps) triggered by spikes in the spiking local interneuron show the evoked IPSP in the nonspiking interneuron. Calibration: Vertical: $A, B$, nonspiking interneuron, $10 \mathrm{mV}$; spiking interneuron, $5 \mathrm{mV}$; horizontal: $A, B, 500 \mathrm{msec} ; C, 14 \mathrm{msec}$.
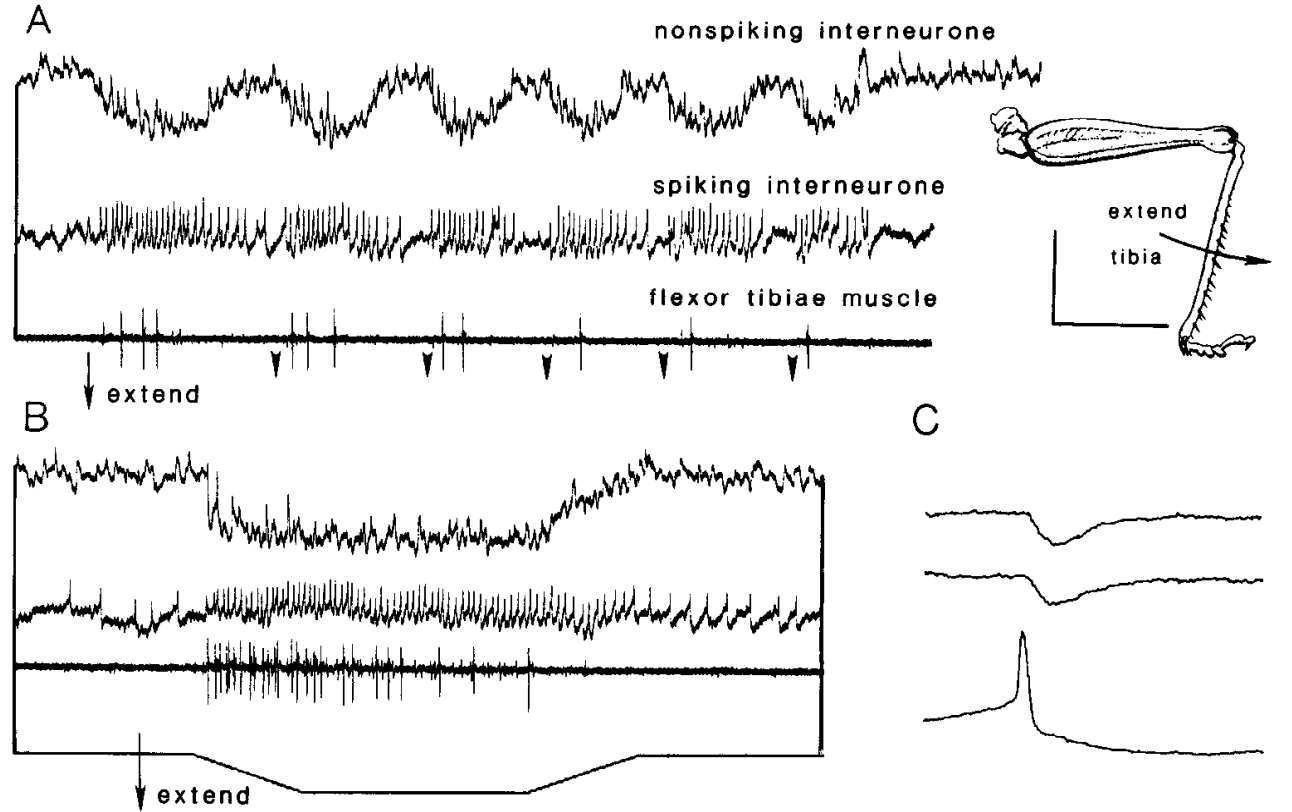

IPSP follows at a short latency in the nonspiking interneuron (Fig. 2C).

The latency between the peak of the spike in a spiking local interneuron excited by either extero- or proprioceptors and the start of an IPSP in a nonspiking interneuron is $0.6 \pm 0.12 \mathrm{msec}$ (mean $\pm \mathrm{SD}, n=26$ pairs of interneurons). The recordings from the spiking local interneurons are, however, made in the soma, which, as judged by the amplitude of the spike, is distant from the spike-initiating region. A $30 \mathrm{mV}$ spike recorded in a neuropilar process is only $5 \mathrm{mV}$ when recorded simultaneously in the soma (Fig. $3 A$ ). Synaptic potentials are also reduced in amplitude and have slower rise times when recorded at the soma (Fig. 3, $B, D, E$ ). Moreover, the peak of the spike is delayed by as much as $0.7 \mathrm{msec}$ at the soma relative to that in the neuropil (Fig. 3C). It is likely that the output synapses onto a nonspiking interneuron are closer to the neuropil recording site in this experiment than to the soma. Therefore, these observations set the likely lower limit for the synaptic delay at $0.6 \mathrm{msec}$ and the upper limit at $1.3 \mathrm{msec}$. The short, consistent synaptic latency and the reliability with which the IPSPs follow the presynaptic spikes indicate that the connections from spiking to nonspiking interneurons are direct.

\section{One-way interactions}

Direct interactions between spiking and nonspiking local interneurons are one-way and are dependent on the occurrence of spikes in the spiking interneuron. In the pair of interneurons shown in Figure 4, a pulse of current injected into the spiking interneuron that is insufficient to evoke spikes has no effect on a nonspiking interneuron (Fig. 4A). The synapse, therefore, does not transmit graded signals generated in this way. With greater currents that evoke spikes, a corresponding number of IPSPs is evoked in the nonspiking interneuron (Fig. $4 B$ ). The greater the current, the more spikes are evoked and the more IPSPs are produced in the nonspiking interneuron (Fig. 4C). A strict 1:1 relationship is maintained between presynaptic spikes and IPSPs. Reversing the experimental arrangement so that current is in- jected into the nonspiking interneuron produces no effect on the spiking interneuron (Fig. $4 D$ ). The graded changes in the membrane potential of the nonspiking interneuron are unable to alter the steady frequency of spikes in the spiking interncuron or to modulate its membrane potential in any way. They are, however, sufficient to excite or inhibit postsynaptic motor neurons or other nonspiking interneurons (Burrows and Siegler, 1978; Burrows, 1979).

Nevertheless, if the depolarization of the nonspiking interneuron evokes a movement, the resulting sensory feedback may alter the membrane potential of the spiking interneuron and give the appearance of a reciprocal interaction. For example, the nonspiking interneuron in Figure 5 evokes a levation of the tarsus and a flexion of the tibia when depolarized by a pulse of current. A spiking local interneuron recorded simultaneously is excited by hairs on the dorsal femur and by proprioceptors activated on levation of the tarsus. Therefore, when the nonspiking interneuron is depolarized and causes a movement of the tarsus, the spiking local interneuron is also depolarized and spikes (Fig. 5A). If the tarsus is held in a more levated position so that movement cannot occur, the spiking local interneuron is excited when current is injected into the nonspiking interneuron, presumably because the tarsal levator muscle still produces force (Fig. $5 B$ ). By contrast, a depolarization of the nonspiking interneuron that does not change the force produced by the tarsal muscles has no effect on the spiking interneuron. The excitation of the spiking interneuron must therefore result from the afference that is caused by the movement of the tarsus or the change in force of its muscles.

The interaction between these two interneurons is nevertheless complex because the spiking local interneuron directly inhibits the nonspiking interneuron (Fig. 5, C, D). Therefore, a tarsal levation initiated by this nonspiking interneuron will evoke spikes in the spiking local interneuron, which will in turn inhibit the nonspiking interneuron initiating the movement. The interaction would appear to represent a mechanism for regulating the extent of the levation movement. 

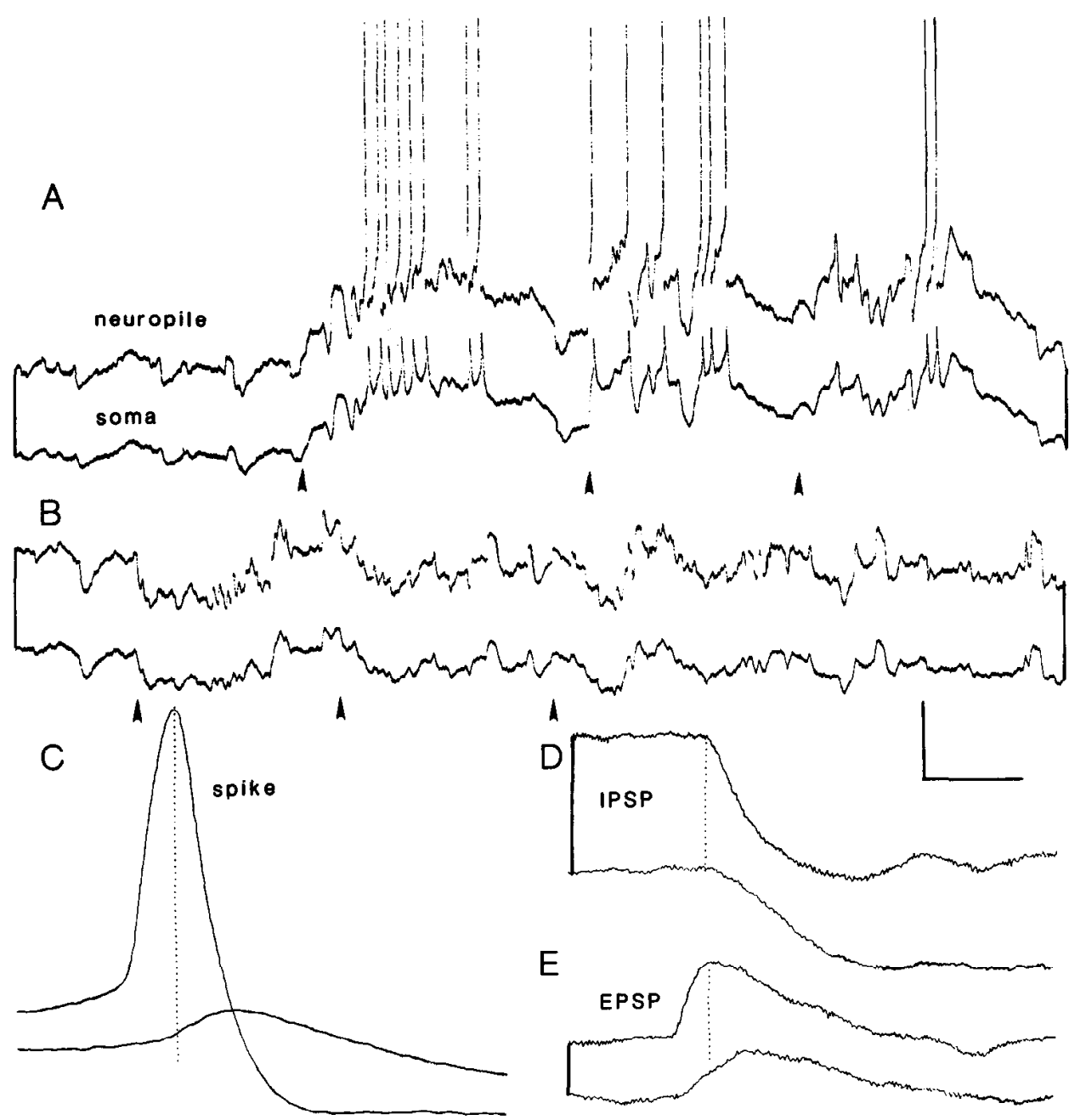

Figure 3. Simultaneous recordings from a neuropilar branch (upper traces) and from the soma (lower traces) of a spiking local interneuron. $A$, Imposed depressions of the tarsus (arrows) lead to depolarizing potentials and spikes that are both faster-rising and larger at the neuropilar electrode. $B$, IPSPs evoked by touching the spurs at the tibiotarsal joint are also faster and larger in the neuropil. $C$, Single sweep triggered by the rising phase of the spike. The vertical dotted line indicates the peak of the spike recorded at the neuropilar site. $D$, An IPSP showing the sharper onset (dotted line) and faster rise time at the neuropil electrode. $E$, An EPSP showing its delayed peak (dotted line) at the soma electrode. Calibration: Vertical: $A-C, 10 \mathrm{mV} ; D, E$, $2 \mathrm{mV}$; horizontal: $A, B, 250 \mathrm{msec} ; C$, $1.6 \mathrm{msec} ; D, E, 8.2 \mathrm{msec}$.

\section{Convergence of inputs onto a nonspiking interneuron}

The inhibition of certain nonspiking interneurons when particular arrays of receptors are stimulated is explained by an inhibitory connection from only a single spiking interneuron (Fig. 6). One of the spiking interneurons excited by hairs on the dorsal femur makes an inhibitory connection with a nonspiking interneuron whose output effects are to inhibit the levator tarsi motor neuron (Fig. 6A). If this spiking interneuron is hyperpolarized by a steady current and the same mechanical stimulus repeated, only a few spikes are evoked and a correspondingly reduced number of IPSPs occurs in the nonspiking interneuron (Fig. $6 B$ ).
A

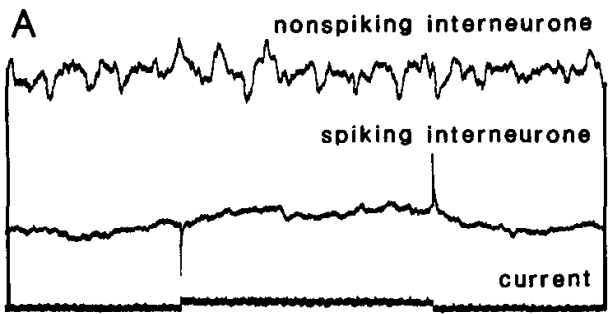

C

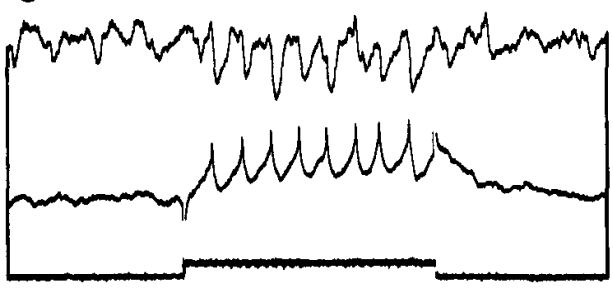

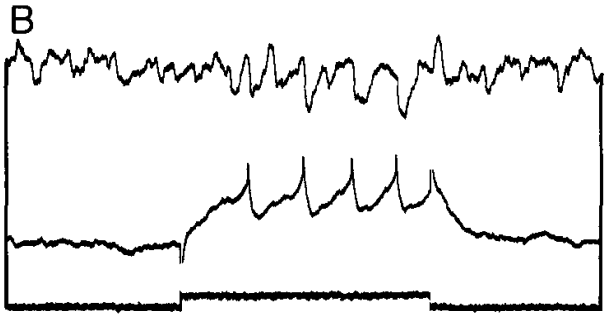

D

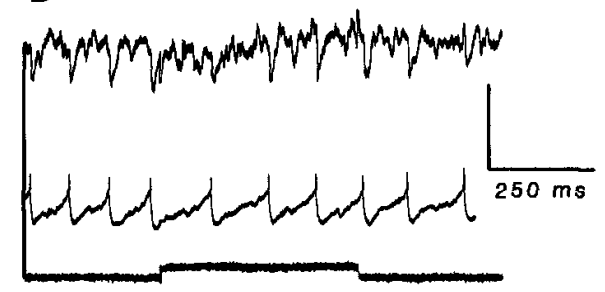

Figure 4. The interaction between 2 interneurons is one-way, and requires spikes in the spiking local interneuron. $A$, A pulse of current injected into the spiking local interneuron by means of a balanced bridge circuit that is insufficient to evoke spikes fails to evoke an effect in the nonspiking interneuron. $B$, When spikes are evoked, IPSPs occur in the nonspiking interneuron. $C$, The greater the current, the more spikes are evoked and correspondingly more IPSPs occur in the nonspiking interneuron. $D$, Injecting a depolarizing pulse of current into the nonspiking interneuron has no effect on the frequency of spikes in the spiking local interneuron. The interneurons are those in Figure 1. Calibration: Vertical nonspiking interneuron, $4 \mathrm{mV}$; spiking interneuron, $10 \mathrm{mV}$. 

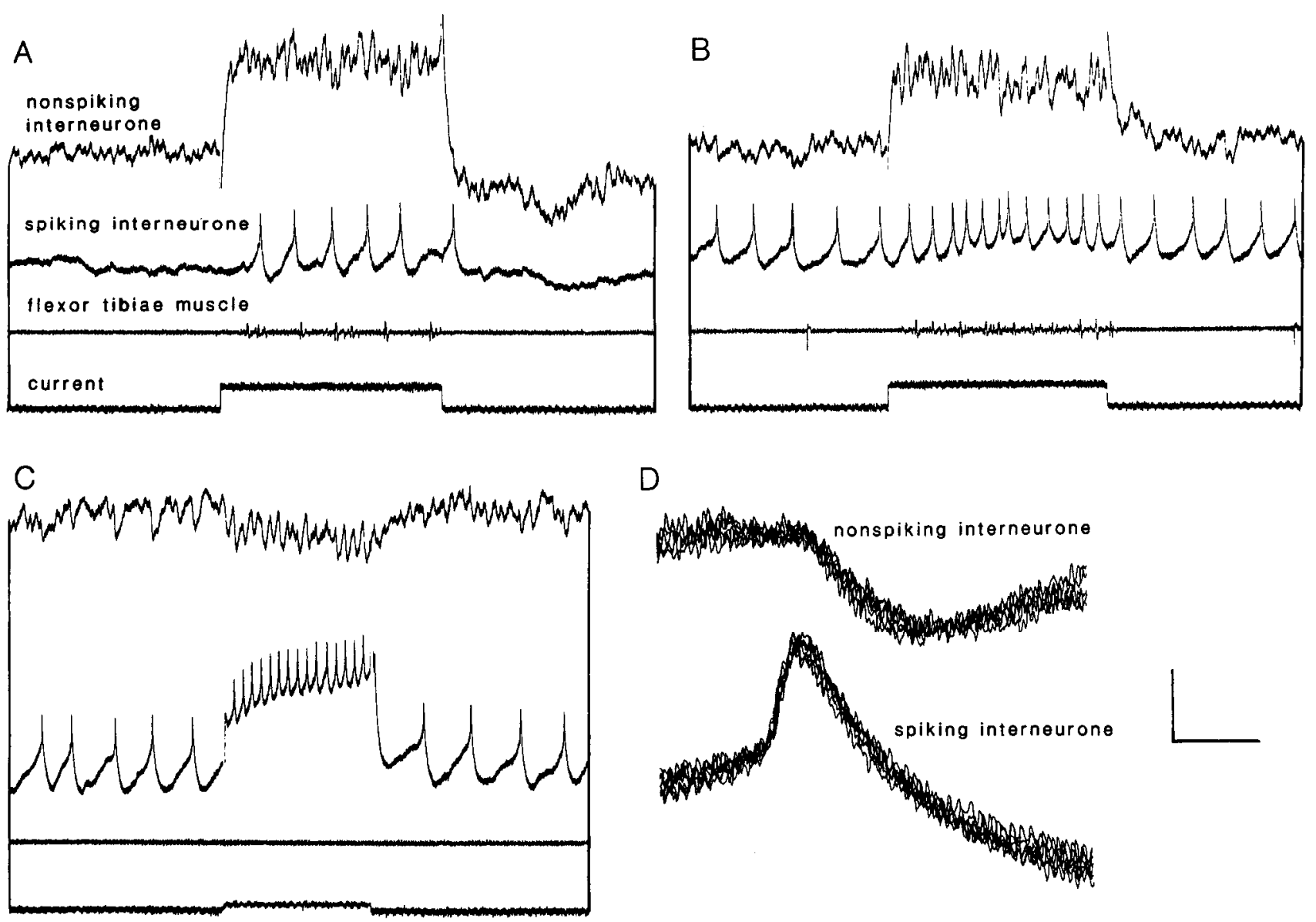

Figure 5. A reciprocal interaction between 2 local interneurons. $A$, Depolarization of the nonspiking interneuron (first trace) evokes a levation of the tarsus and a flexion of the tibia (myogram from the flexor tibiae muscle, third trace) and spikes in the spiking local interneuron (second trace). $B$, The tarsus is held, but the same pulse of current still causes an increase in the frequency of spikes in the spiking interneuron. $C$, Depolarizing the spiking local interneuron increases the frequency of IPSPs in the nonspiking interneuron. $D$. Multiple sweeps triggered by the spike show a consistent IPSP after a constant latency in the nonspiking interneuron. Calibration: Vertical, $A-C, 5 \mathrm{mV} ; D, 1.25 \mathrm{mV}$, current, $8 \mathrm{nA}$; horizontal: $A-C, 250 \mathrm{msec} ; D, 4.1 \mathrm{msec}$.

Thereforc, the information that a stimulus has becn received by this region of the leg is fed to this nonspiking interneuron by a single spiking interneuron.

By contrast, the inhibition of other nonspiking interneurons clearly results from the convergence of inputs from several spiking interneurons (Fig. 7). A nonspiking interneuron whose motor effect is to excite the levator tarsi motor neuron is inhibited when the tibia is forcibly extended. A spiking interneuron is excited by this movement (Fig. $7 A$ ) and makes an inhibitory connection with the nonspiking interneuron (Fig. $7 D$ ). Hyperpolarizing this spiking interneuron to reduce the frequency of evoked spikes and repeating the movement have little effect on the inhibition of the nonspiking interneuron (Fig. 7B). Hyperpolarizing the interneuron still further so that an imposed movement of the tibia evokes only a few spikes reduces, but does not abolish, the inhibition of the nonspiking interneuron (Fig. 7C). Other spiking interneurons excited by an extension of the tibia must converge to inhibit this nonspiking interneuron.

\section{Divergence of connections made by a spiking local interneuron}

To assess how widely the outputs of a particular spiking local interneuron are distributed among the population of nonspiking interneurons, a recording from one spiking interneuron was maintained while several nonspiking interneurons were sampled in the same locust. In one example, a spiking local interneuron excited by touching hairs on the ventral surface of the femur was recorded while 9 nonspiking interneurons with inputs associated with a mechanical stimulus to the femur were sampled successively. The spiking interneuron makes direct inhibitory connections with only 4 of the 9 nonspiking interneurons (Fig. $8 A$ ). Touching the ventral femur evokes a burst of spikes in the spiking interneuron and a sharp burst of IPSPs in the nonspiking interneuron labeled 1 in Figure 8, but there is no connection between the 2 interneurons (Fig. $8, B, C$ ). Nonspiking interneuron 2 also shows a burst of IPSPs when the hairs are touched that closely parallels the pattern of spikes in the spiking interneuron (Fig. 8D). Again, no direct connection exists, and the assumption must be that the IPSPs result from spikes in another spiking interneuron with an overlapping receptive field. Nonspiking interncurons $6-9$, by contrast, all receive a direct input from the spiking local interneuron. In interneuron 6 , the IPSPs from the spiking interneuron are intermingled with other IPSPs that presumably originate from a second spiking interneuron also excited by this stimulus (Fig. $8 E$ ). The IPSPs in the interneuron 9 are more prominent (Fig. $8 F$ ) and clearly follow each spike with a short and constant latency (Fig. $8 G$ ). These obser- 


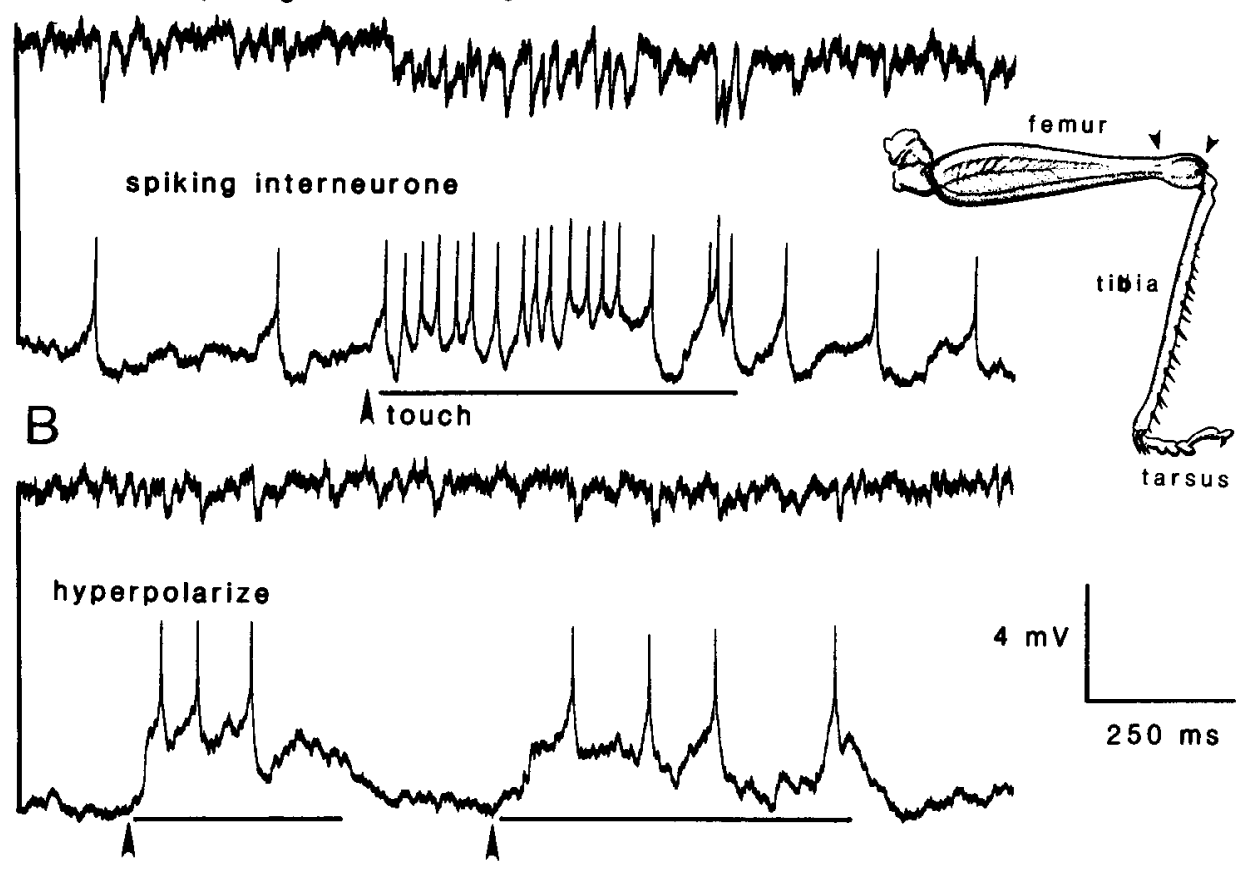

Figure 6. Input from one spiking interneuron explains the inhibition in a nonspiking interneuron when specific hairs on a leg are stimulated. $A$, Touching hairs on the dorsal femur (horizontal bar) evokes spikes in the spiking local interneuron that are each followed by IPSPs in the nonspiking interneuron. $B$, The spiking interneuron is held hyperpolarized by a steady current and the same stimulus repeated twice (bars). Only a few spikes now are evoked by each stimulus, and the inhibition in the nonspiking interneuron is correspondingly reduced. IPSPs from other sources still occur in the interneuron. vations suggest great specificity in the connections made between the local interneurons, even though their receptive fields may overlap.

\section{Spatial information is preserved by specific connections of spiking local interneurons}

To assess the specificity of connections made by the spiking local interneurons, a recording from one nonspiking interneuron was maintained while several spiking interneurons were sampled. In Figure 9, 6 of 7 spiking interneurons have at least part of their receptive fields in common with that of the nonspiking interneuron. For example, spiking interneuron 4 is excited by inputs from the ventral tibia, and the nonspiking interneuron is inhibited. There is, however, no connection between these 2 interneurons. Similarly spiking interneurons excited by extension of the tibia (7), dorsal femoral hairs (1), and ventral tarsal hairs ( 2 and 5 ) do not synapse with the nonspiking interneuron. Only the spiking interneuron excited by depression of the tarsus (6) makes a connection. The remainder of the inhibitory receptive field of the nonspiking interneuron must therefore be derived from spiking interneurons other than those sampled. Observations indicate that the receptive field of a nonspiking interneuron is formed by highly specific connections from spiking interneurons with the appropriate receptive fields. The observation that the receptive fields of a pair of interneurons overlap is not in itself sufficient to predict connectivity.
A

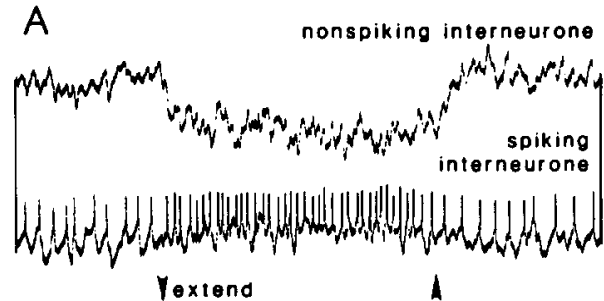

C

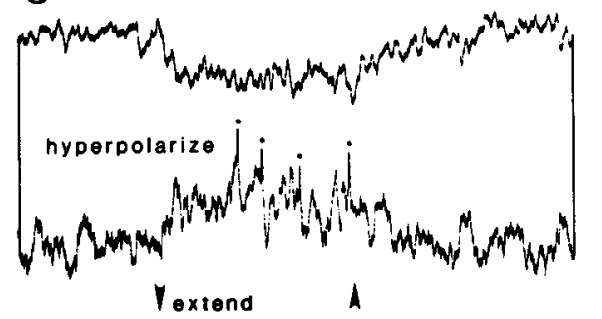

B

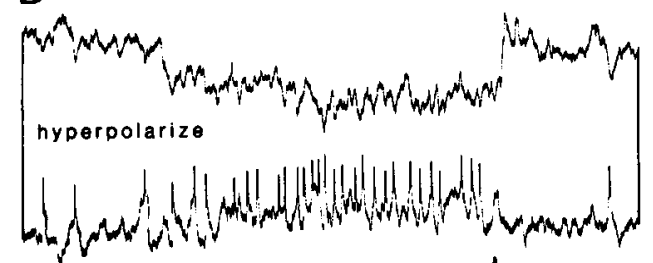

Toxtend
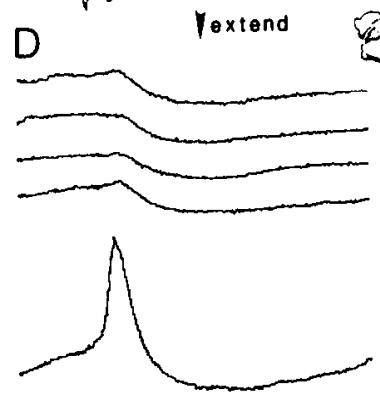

Figure 7. Convergence of inputs from spiking local interneurons onto a nonspiking interneuron. $A$, An imposed extension of the tibia increases the frequency of spikes in a spiking local interneuron and hyperpolarizes a nonspiking interneuron. $B$, A steady hyperpolarizing current is applied to the spiking interneuron and the same extension movement of the tibia is imposed. The spiking interneuron spikes at a lower frequency, but the nonspiking interneuron is nevertheless hyperpolarized. $C$, More current is injected, so that the same movement now only evokes a few spikes (dotted). The hyperpolarization of the nonspiking interneuron is reduced, but is still substantial. $D$, Signal averages showing the synaptic connection between these 2 interneurons. Each of the 4 averaged IPSPs is the result of 128 occurrences of spikes. Calibration: vertical: $A-C, 5 \mathrm{mV}$; horizontal: $A-C, 250 \mathrm{msec} ; D, 14 \mathrm{msec}$. 
A
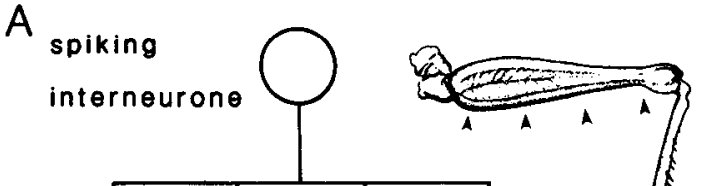

B int 1
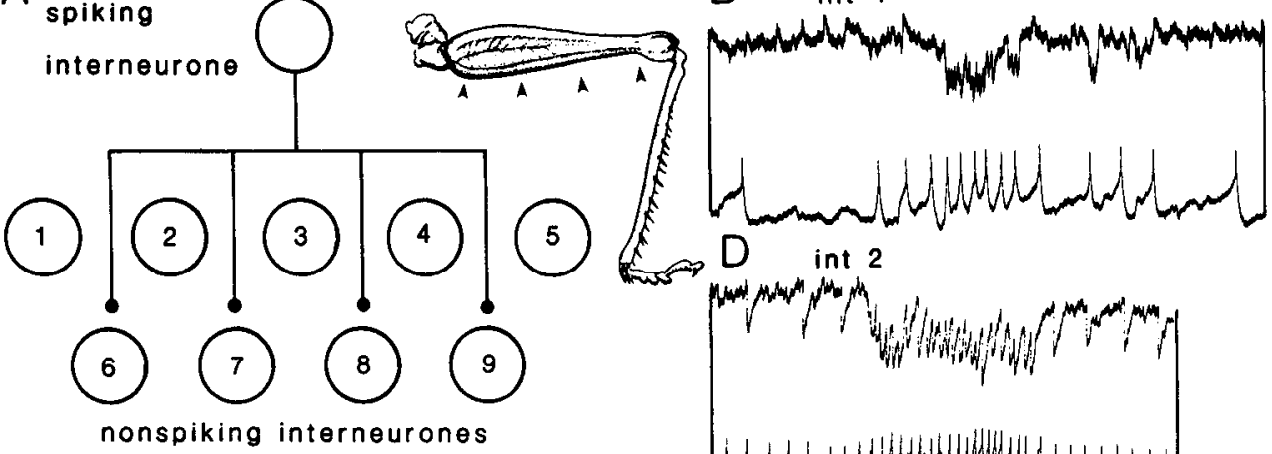

C int 1
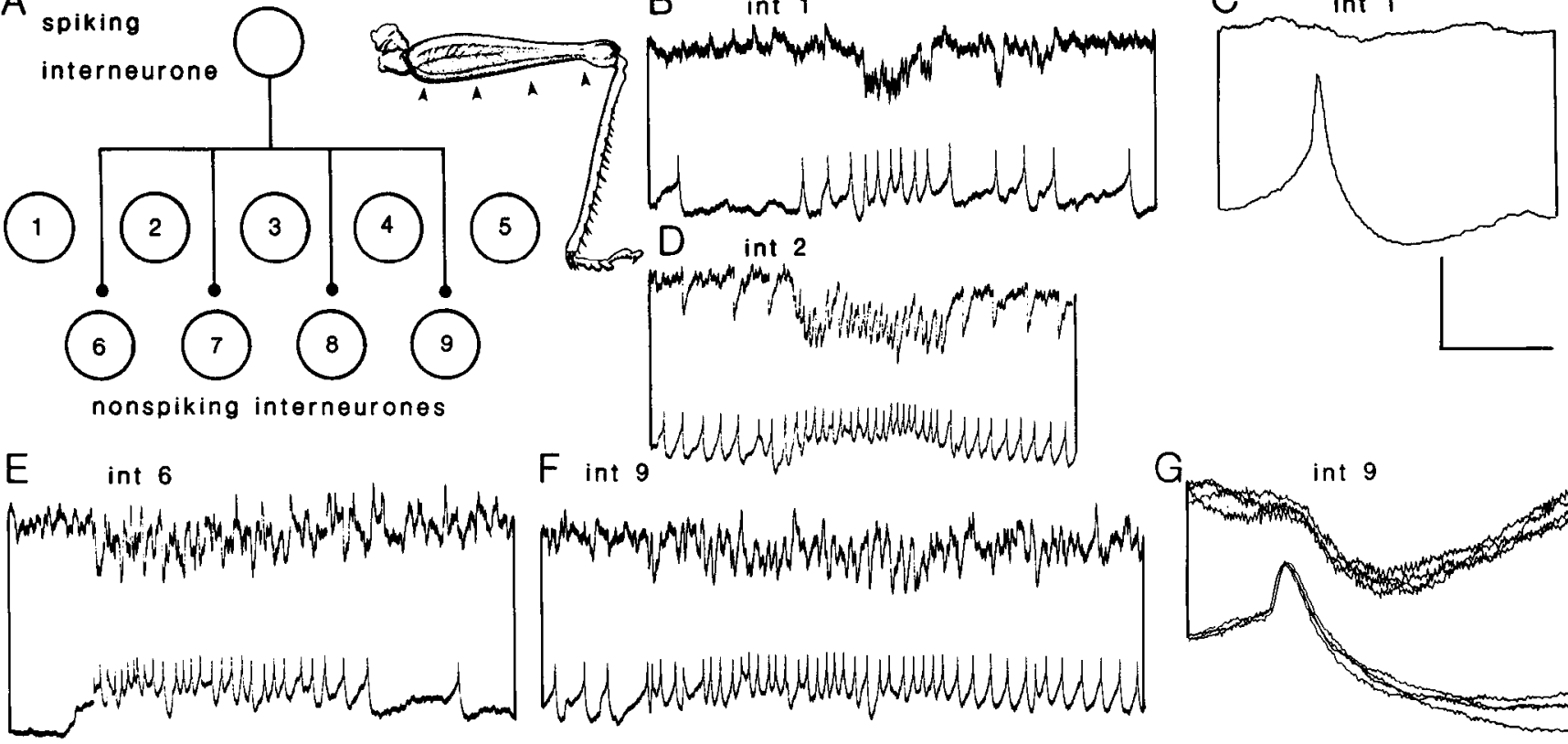

$F$ int 9
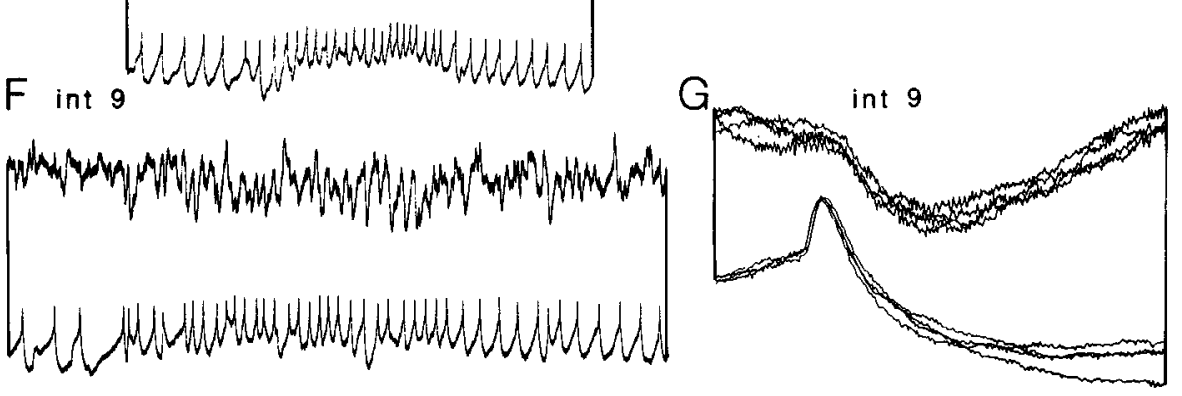

Figure 8. Divergence of connections from a spiking local interneuron to nonspiking local interneurons. $A$, In one locust, a spiking interneuron excited by touching hairs on the ventral femur makes inhibitory connections with 4 or the 9 nonspiking interneurons. $B$, The tactile stimulus evokes a burst of spikes and a more rapid burst of IPSPs in nonspiking interneuron 1. $C$, Signal averaging (64 sweeps) shows there is no connection. $D$, The same stimulus evokes IPSPs in nonspiking interneuron 2, but there is again no connection between these 2 interneurons. $E$, Spikes in the spiking interneurons are followed by IPSPs in nonspiking interneuron $6 . F$, IPSPs in interneuron 9 occur whenever the spiking interneuron spikes. $G$, Superimposed sweeps triggered by spikes in the spiking interneuron show the consistent IPSPs in this nonspiking interneuron. Calibration: vertical: $B, D-F$, nonspiking interneuron, $5 \mathrm{mV} ; G, 2.5 \mathrm{mV} ; B, D-F$, spiking interneuron, $10 \mathrm{mV} ; G, 5 \mathrm{mV}$; horizontal: $B, D-F, 250 \mathrm{msec} ; C, 28$ msec; $G, 8.2 \mathrm{msec}$.

\section{Discussion}

\section{Connections between the interneurons}

Whenever synaptic connections have been found between pairs of spiking and nonspiking local interneurons, they have proved to be inhibitory and unidirectional: The spiking local interneuron inhibits the nonspiking interneuron. Apparent reciprocal effects are explained by peripheral feedback loops. The imposed depolarization of a nonspiking neuron leads to contraction of a set of muscles, and the forces or movements they bring about change the afferent input to a spiking local interneuron.

Is the inhibition of a nonspiking interneuron by a spiking one due to a direct synaptic connection? The latency between the peak of a spike in the soma of a spiking local interneuron and the start of an IPSP in a neuropilar process of a nonspiking interneuron is $0.6 \mathrm{msec}$. The true latency is somewhat longer than this because the spike at the soma is delayed relative to that recorded in the neuropil. The actual spike-initiating sitc is not known, but the output synapses are likely to be made from the dorsal branches, where electron microscopy has shown a preponderance of output over input synapses (Watson and Burrows, 1985). The soma is separated from all synaptic sites by a long, thin primary neurite so that an electrode in a neuropilar branch is likely to be closer to the output synapses. Allowances for the conduction of the spike within the spiking interneuron indicate a maximum latency of $1.3 \mathrm{msec}$. No comparable estimate is available for the conduction of the IPSP to the recording site in a neuropilar process of the nonspiking interneuron. If the recording site is distant from the synaptic site, any resistance will delay the IPSP and therefore contribute to an underestimate of the synaptic latency. The latency suggests that there is sufficient time for only a single chemical synapse in the pathway. The latency is similar to that measured between a spiking local interneuron and a motor neuron in this ganglion (Burrows and Siegler, 1982), a spiking local interneuron and an intersegmental interneuron in the mesothoracic ganglion (Laurent, 1987), and other supposed direct connections in insect ganglia (Robertson and Pearson, 1985; Selverston et al., 1985). Moreover, each spike in a presynaptic spiking local interneuron is always followed by an IPSP in a nonspiking interneuron with a consistent latency. All observations are consistent, therefore, with the connection being direct and chemically mediated. The anatomy is also consistent with this interpretation, for the branches of the two types of interneuron overlap in dorsal and lateral neuropil (Siegler and Burrows, 1984; Watkins et al., 1985).

\section{Receptive fields of nonspiking interneurons}

Nonspiking interneurons are excited by inputs from certain mechanoreceptors of a leg and inhibited when others are stimulated. The organization of the excitatory receptive fields will be described in later papers. The inhibitory receptive fields are determined by the excitatory receptive fields of the presynaptic spiking local interneurons. Hyperpolarizing a single spiking interneuron can even abolish the inhibition of a nonspiking neuron when an array of receptors is stimulated, so that it alone provides an adequate explanation for that part of the inhibitory receptive field. Other nonspiking interneurons have receptive fields derived from the convergent inputs from several presynaptic spiking interneurons. Hyperpolarizing any one of these spiking interneurons does not abolish the receptive field but 

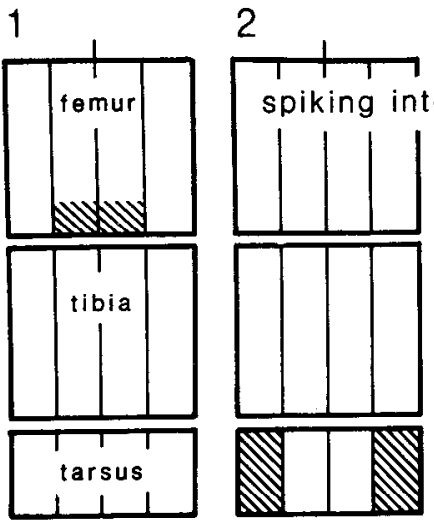

\section{3}
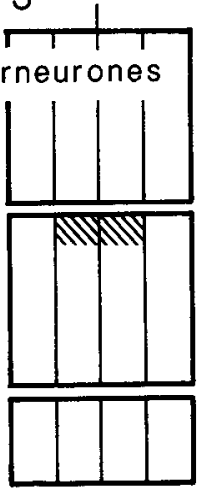

4

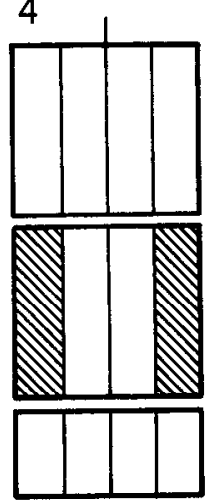

5

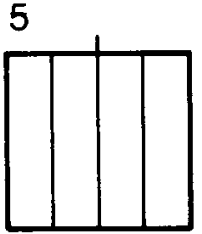

6
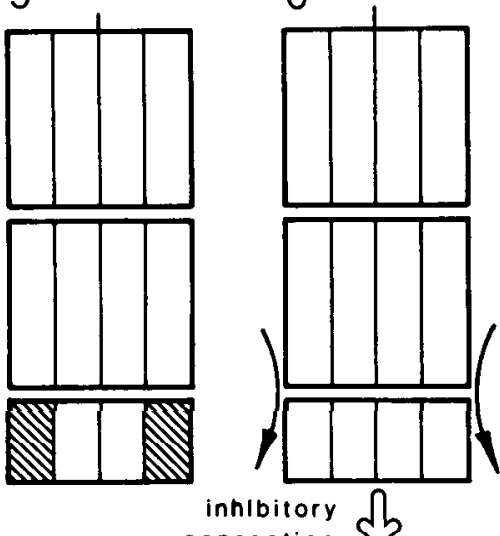

connection

nonspiking

interneurone
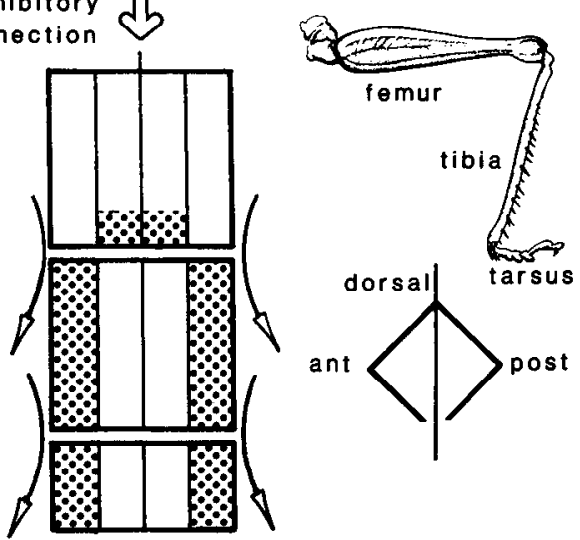

Figure 9. Specificity of connections made by spiking local interneurons. In one locust a recording was maintained from a nonspiking interneuron while 7 spiking interneurons were sampled. All except spiking interneuron 3 have regions of their receptive fields in common with the nonspiking interneuron, and yet only interneuron 6 inhibits it. Each interneuron is represented by a diagram of its receptive field, constructed as if a hindleg were opened by a ventral midline incision along its whole length (shown in the diagrammatic transverse section at bottom right) and then spread out. The femur, tibia, and tarsus are represented by 4 sectors: ventral anterior and posterior, and dorsal anterior and posterior. Regions providing excitation are crosshatched; those providing inhibition are stippled. Extension movements of a joint (extension of the tibia or depression of the tarsus) that excite are indicated by solid, outward-pointing arrows, those that inhibit by an open arrow. The same conventions are used in Figures 10 and 11.

merely reduces the evoked inhibition. The receptive fields of pairs of interneurons with inhibitory connections are summarized in Figure 10. In general, the inhibitory receptive field of a nonspiking interneuron is no more complex than the excitatory
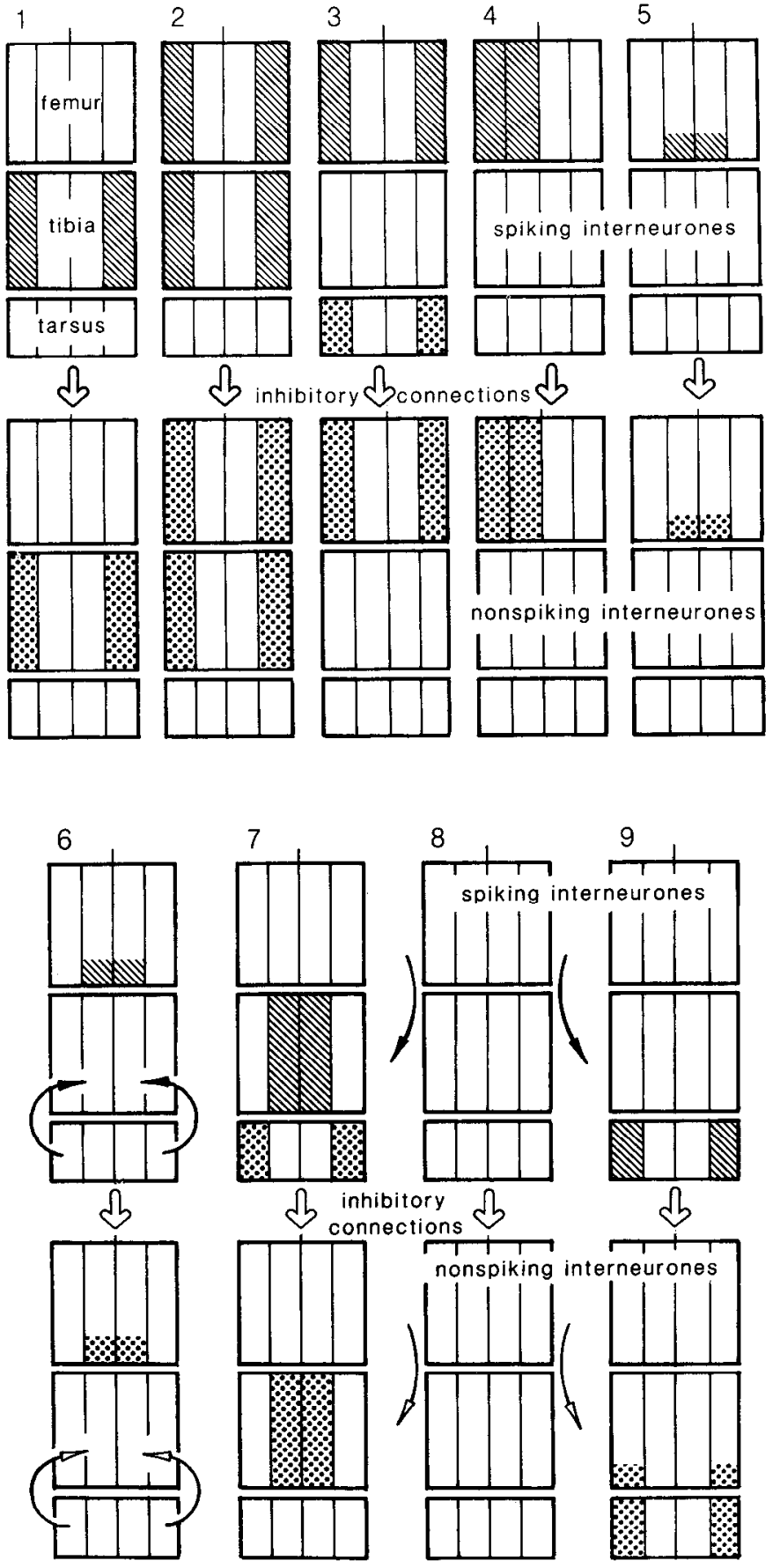

Figure 10. Comparison of the receptive fields of nonspiking and spiking local interneurons. In each of the 9 pairs, the spiking local interneuron makes an inhibitory connection with the nonspiking interneuron. For most pairs, this results in a simplc transformation of an cxcitatory receptive field for the spiking interneuron to an inhibitory one for the nonspiking interneuron. The outward-facing arrows indicate an extension of a joint, the inward-facing arrows a flexion.

field of a presynaptic spiking interneuron. The implication is that spatial information about the mechanoreceptors on a leg is retained through these pathways.

The connections between the local interneurons nevertheless involve both divergence and convergence of signals, but with the overriding constraint that the spatial information be preserved. Divergence is illustrated by the fact that touching hairs on the dorsal femur excites a spiking local interneuron that then 

the inhibitory interactions between the local interneurons. The receptive fields and the inhibitory connections are related to the motor output that is expressed when a nonspiking interneuron is depolarized. $A$, A spiking interneuron recorded with 3 nonspiking interneurons in the same locust. It makes an ing interneuron that causes flexion of the tibia and with an interneuron whose output could not be defined, but does not connect with one causing extension of the tibia. $B$. Two spiking interneurons converge on a nonspiking interneuron that causes flexion of the tibia and levation of the tarsus. $C$, A spiking interneuron making an inhibitory connection with a nonspiking interneuron that causes cxtension of the tibia. Note the different receptive field of this nonspiking interneuron as compared to that in $A$ with the same motor effect. $D$, Two different spiking interneurons that converge on a nonspiking interneuron which also causes flexion of the tibia and levation of the tarsus. Note that the nonspiking interneuron has a different receptive field from that in $B$.
Figure 11. The behavioral context for inhibitory connection with a nonspik-

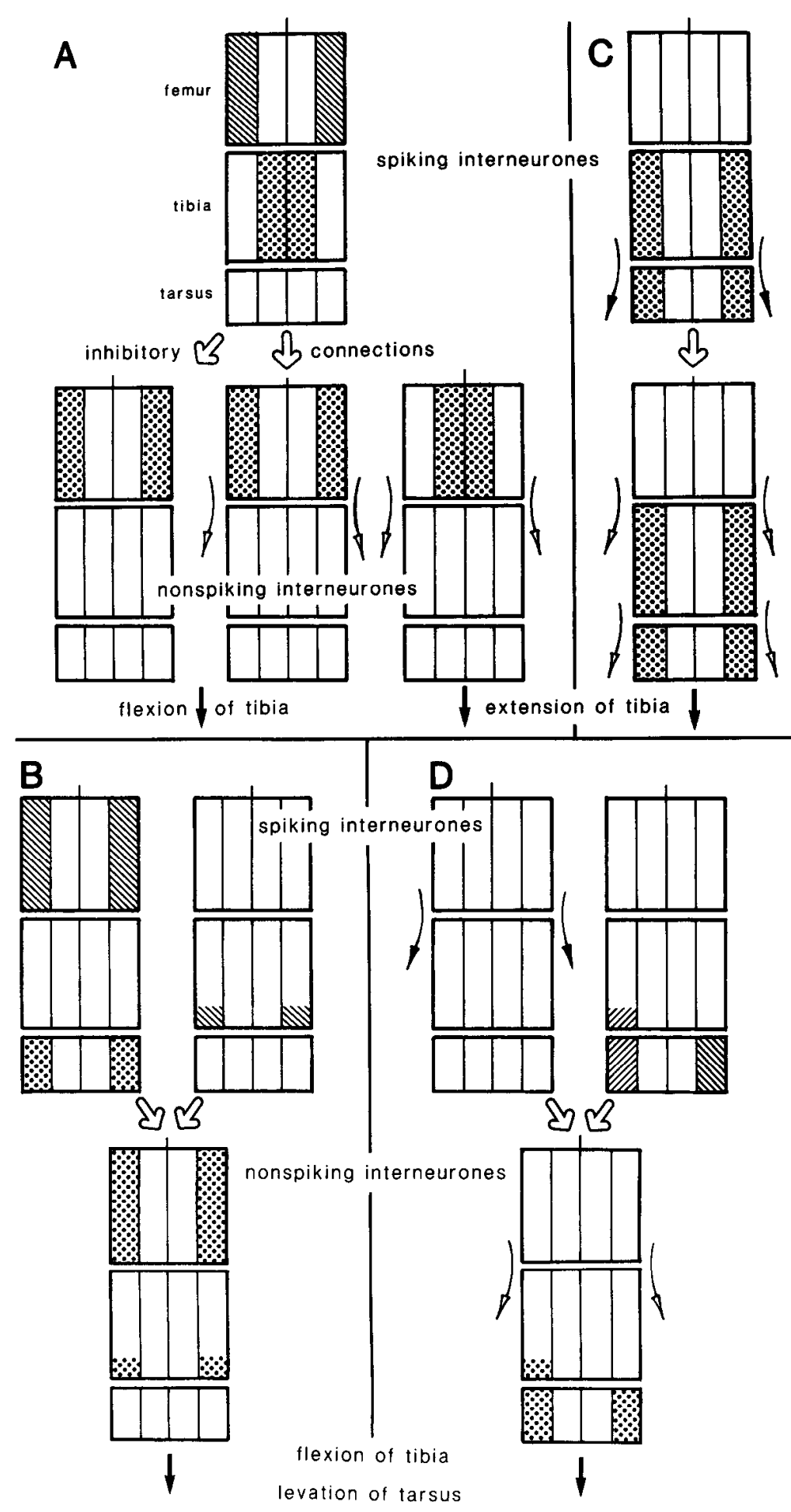

makes inhibitory connections with several nonspiking local interneurons (Fig. 8). The same stimulus also excites other spiking interneurons, which make further divergent connections. Convergence is illustrated by the fact that several spiking interneurons inhibit one nonspiking interneuron. The specificity of these connections is revealed when comparisons are made between the detailed receptive fields of the 2 types of interneurons. Thus, for example, not all spiking interneurons excited by the dorsal femur converge on the same nonspiking interneuron, and conversely, nonspiking interneurons with large receptive fields do not receive inputs from all spiking interneurons with parts of their receptive fields in common (Fig. 9). Information from different parts of the leg is thus preserved at the level of the nonspiking interneurons by restricted connections from spiking interneurons. A specific movement of the leg could thereforc result when a particular array of receptors is stimulated because the nonspiking interneurons make inhibitory connections with other nonspiking interneurons to exclude unwanted movements during the performance of a selected one (Burrows, 1979), and because they connect with sets of motor neurons (Burrows, 1980). 


\section{Do the pathways explain known reflexes?}

Avoidance reflexes and resistance reflexes form two broad categories of local reflex. An avoidance reflex moves the leg away from a mechanical stimulation of exteroreceptors on a leg, with the precise form of movement depending upon the spatial location of the stimulated receptors (Siegler and Burrows, 1986). A resistance reflex is initiated by proprioceptors and ensures that an imposed movement of a joint is resisted by an opposing muscular force. Do the pathways between the spiking and nonspiking interneurons contribute to these reflexes? The receptive fields of 6 spiking interneurons that inhibit nonspiking interneurons with known motor effects are summarized in Figure 11 .

Touching hairs on the ventral femur leads to a reflex in which the trochanter is levated, the tibia extended, and the tarsus depressed. This stimulus also excites a spiking local interneuron that inhibits 2 nonspiking interneurons but has no effect on a third (Fig. 11A). Both nonspiking interneurons receiving an inhibitory connection excite flexor tibiae motor neurons, whereas the one that does not receive a connection excites the antagonistic extensor motor neurons (Fig. 11A). Therefore, when the ventral femur is touched, the flexor action of the 2 nonspiking interneurons is suppressed and the tibia is allowed to extend. The nonspiking interneuron that excites extensor motor neurons has an inhibitory receptive field on the dorsal femur, which is commensurate with its role in a reflex of opposite sign.

Touching the ventral femur or the ventral tibia also excites other spiking local interneurons. These, in turn, inhibit a nonspiking interneuron that excites both flexor tibiae and levator tarsi motor neurons (Fig. 11B), thus permitting tarsal depression and tibial extension. At the same time, inputs from receptors on the ventral tibia excite other spiking local interneurons that make direct inhibitory connections with the levator tarsi motor neuron (Burrows and Siegler, 1982). Therefore, in this reflex, inhibition of the levator motor neuron is achieved by two parallel pathways, the first involving 3 neurons (sensory, spiking local, and motor), the second 4 neurons (an additional nonspiking interneuron).

Similar analyses of the pathways from proprioceptors show that the connections between the local interneurons are appropriate in the context of resistance reflexes. For example, a forced extension of the tibia excites spiking local interneurons, which then inhibit particular nonspiking interneurons, some of which would excite the extensor tibiae motor neurons (Fig. 2). The inhibition therefore ensures that the imposed movement can be resisted by the antagonistic flexor neurons. Similarly, a nonspiking interneuron that causes extension of the tibia is inhibited by a spiking local interneuron that is itself excited by an imposed depression of the tarsus (Fig. $11 \mathrm{C}$ ). This stimulus excites the antagonistic levator tarsi and flexor tibiae motor neurons by a compensatory interjoint response. The inhibitory connection therefore suppresses any residual extensor force, allowing tibial flexion to proceed.

While the majority of connections can be explained by their roles in reflexes that are already known, some cannot. For example, a spiking local interneuron excited by tibial extension inhibits a nonspiking interneuron that excites flexor tibiae and levator tarsi motor neurons (Fig. $11 D$ ). This pathway would result in inhibition of flexors, the opposite of what is required by the resistance reflex. It is a pathway appropriate for an assistance reflex. Nevertheless, this nonspiking interneuron is also inhibited by a spiking local interneuron that receives excitatory iputs from receptors on the ventral tarsus. This pathway does explain the avoidance reflex elicited by these receptors.

\section{Organization of local circuits}

The striking feature of the pathways revealed is the presence of local neurons with distinct mechanisms of intracellular signaling. The spiking local interneurons receive direct excitatory inputs from afferents (Siegler and Burrows, 1983) and then make inhibitory connections with nonspiking interneurons, which, in turn, inhibit each other (Burrows, 1979) and either inhibit or excite motor neurons (Burrows, 1980). Do the different roles so far revealed for the two types of interneuron give any clues as to why they should be needed? A major role for the spiking interneurons is to map the leg as a series of receptive fields arranged to preserve spatial information for use in local reflexes (Siegler and Burrows, 1986). As many as 10,500 afferent fibers enter the metathoracic ganglion from a hindleg (Siegler and Burrows, 1983), and each receptive field contains a large number of receptors. The presence of perhaps only 100 spiking local interneurons in the midline group suggests considerable convergence, and that a function of these interneurons is to reduce complexity. It seems logical, therefore, to build into this function a threshold device, the spike-generating mechanism, that will allow summation of inputs before an output is delivered to the next neuron. The finding that imposed depolarizations of a spiking interneuron which do not evoke spikes fail to affect the postsynaptic nonspiking interneuron is in keeping with this suggested role. The spike threshold avoids an unwanted motor response to a few sensory spikes, but also allows plasticity in the reflexes because the threshold can be altered by other synaptic inputs.

By contrast, a major role for the nonspiking interneurons is to control the output of sets of motor neurons (Burrows, 1980). The requirement here is for delicate changes in muscular force, particularly in changes of posture, which is precisely met by the graded and sustained release of transmitter from the nonspiking interneurons. The design requirements for a variable filter at the input stage and for a smoothly variable gain control at the output stage of reflex pathways that adjust posture and locomotion are therefore met, respectively, by the spiking and nonspiking local interneurons.

\section{References}

Blight, A. R., and R. Llinás (1980) The non-impulsive stretch-receptor complex of a crab: A study of depolarization-release coupling at a tonic sensorimotor synapse. Phil. Trans. R. Soc. Lond. [Biol.] 290: 219-276.

Brogan, R. T., and R. M. Pitman (1981) Axonal regeneration in an identified insect motoneurone. J. Physiol. 319: 34P-35P.

Burrows, M. (1979) Graded synaptic transmission between local premotor interneurons of the locust. J. Neurophysiol. 42: 1108-1123.

Burrows, M. (1980) The control of sets of motoneurones by local interneurones in the locust. J. Physiol. 298: 213-233.

Burrows, M. (1985) The processing of mechanosensory information by spiking local intcrneurones in the locust. J. Neurophysiol. 54: 463478.

Burrows, M. (1987) Parallel processing of proprioceptive signals by spiking local interneurons and motor neurons in the locust. J. Neurosci. 7: 1064-1080.

Burrows, M., and M. V.S. Siegler (1978) Graded synaptic transmission between local interneurones and motoneurones in the metathoracic ganglion of the locust. J. Physiol. 285: 231-255.

Burrows, M., and M. V. S. Siegler (1982) Spiking local interneurons mediate local reflexes. Science 217: 650-652. 
Burrows, M., and M. V. S. Siegler (1984) The morphological diversity and receptive fields of spiking local interneurones in the locust metathoracic ganglion. J. Comp. Neurol. 224: 483-508.

Burrows, M., and M. V.S. Siegler (1985) The organization of receptive fields of spiking local interneurones in the locust with inputs from hair afferents. J. Neurophysiol. 53: 1147-1157.

Homma, S. (ed.) (1976) Understanding the stretch reflex. Prog. Brain Res. Vol. 44.

Laurent, G. (1987) Local circuits underlying excitation and inhibition of intersegmental interneurones in the locust. J. Comp. Physiol. (in press).

Pitman, R. M., C. D. Tweedle, and M. J. Cohen (1972) Branching of central neurons: Intracellular cobalt injection for light and electron microscopy. Science 176: 412-414.

Robertson, R. M., and K. G. Pearson (1985) Neural circuits in the flight system of the locust. J. Neurophysiol. 53: 1, 110-128.

Selverston, A. I., H.-U. Kleindienst, and F. Huber (1985) Synaptic connectivity between cricket auditory interneurons as studied by selective photoinactivation. J. Neurosci. 5: 1283-1292.

Siegler, M. V. S., and M. Burrows (1979) The morphology of local nonspiking interneurones in the metathoracic ganglion of the locust. J. Comp. Neurol. 183: 121-148.

Siegler, M. V. S., and M. Burrows (1983) Spiking local interneurons as primary integrators of mechanosensory information in the locust. J. Neurophysiol. 50: 1281-1295.
Siegler, M. V. S., and M. Burrows (1984) The morphology of two groups of spiking local interneurones in the metathoracic ganglion of the locust. J. Comp. Neurol. 224: 463-482.

Siegler, M. V. S., and M. Burrows (1986) Receptive fields of motor neurons underlying local tactile reflexes in the locust. J. Neurosci. 6: 507-513.

Sillar, T., and P. Skorupski (1986) Central input to primary afferent neurones in crayfish, Pacifastacus leniusculus, is correlated with rhythmic motor output of thoracic ganglia. J. Neurophysiol. 55: 678-688.

Skorupski, P., and K. T. Sillar (1986) Phase-dependent reversal of reflexes mediated by the thoracocoxal muscle receptor organ in the crayfish, Pacifastacus leniusculus. J. Ncurophysiol. 55: 689-695.

Taylor, A., and S. Gottlieb (1985) Convergence of several sensory modalities in motor control. In Feedback and Motor Control in Invertebrates and Vertebrates, W. J. P. Barnes and M. H. Gladden, eds., pp. 77-91, Croom Helm, London.

Watson, A. H. D., and M. Burrows (1985) The distribution of synapses on the two fields of neurites of spiking local interneurones in the locust. J. Comp. Neurol. 240: 219-232.

Watkins, B. L., M. Burrows, and M. V. S. Siegler (1985) The structure of locust non-spiking interneurones in relation to the anatomy of their segmental ganglion. J. Comp. Neurol. 240: 233-255. 